\title{
Weekly chemotherapy with cisplatin and paclitaxel in advanced NSCLC: a phase II study
}

\author{
G. Buccheri, D. Ferrigno, M.C. Giordano
}

ABSTRACT: Weekly chemotherapy with cisplatin and paclitaxel in advanced NSCLC: a phase II study. G. Buccheri, D. Ferrigno, M.C. Giordano.

Background. This phase II study was designed to assess the activity and toxicity of administration of the cisplatin/paclitaxel combination in advanced non-small cell lung cancer (NSCLC).

Methods. Eligibility criteria included: age up to $\mathbf{7 0}$ years, pathological diagnosis of NSCLC, inoperable disease or post-operative tumour recurrence, performance status $</=2$, no severe co-morbidity, no previous chemotherapy, and informed consent. Treatment consisted of intravenous infusion of cisplatin, $25 \mathrm{mg} / \mathrm{m}^{2}$, and paclitaxel, $80 \mathrm{mg} / \mathrm{m}^{2}$, every week. Chemotherapy was continued until completion of a 22 -week treatment plan, disease progression, persistent toxicity, or patient refusal.
Results. Forty-nine patients entered the study. They received a median of 14 cycles (range 0-22). For both drugs, the median dose-intensity was $75 \%$ of projected. Toxicity was generally acceptable, and never life threatening. Alopecia was the most common side effect, followed by anemia, leukopenia, and nausea/vomiting. Twenty patients responded $(40.8 \%$ response rate), with three complete, pathologically documented responses. The estimated median time to progression was 35 weeks (95\% CI: 29-41); the median survival time was 56 weeks (95\% CI: not calculable), with a 2-year survival rate of 46.1\%.

Conclusions. When given on a weekly basis, the cisplatin/paclitaxel combination is well tolerated, active, and associated to remarkably long survivals. Monaldi Arch Chest Dis 2006; 65: 2, 75-81.

Keywords: Non-small cell lung cancer, chemotherapy, cisplatin, paclitaxel, first-line treatment.

Struttura Complessa di Pneumologia, Azienda Ospedaliera "S. Croce e Carle”, Cuneo, Italy.

Correspondence: Gianfranco Buccheri, M.D.; Cuneo Lung Cancer Study Group; Struttura Complessa di Pneumologia; Ospedale A. Carle; Azienda Ospedaliera "S. Croce e Carle”; Cuneo, I-12100, Italy; e-mail: buccheri@ culcasg.org, www.culcasg.org

\section{Introduction}

Lung cancer remains the leading cause of cancer-related death [1]. The majority of patients with lung cancer has a non-small cell carcinoma (NSCLC) and present with locally advanced (Stage III) or metastatic disease (Stage IV) [2]. Most of these patients receive chemotherapy, since first-line platinum-based combinations improve survival, palliate symptoms, and ameliorate quality of life [3-6]. Unfortunately, there is no consensus on which drug combination or treatment schedule should be recommend in every day practice [7]. Randomised trials seem to support the use of a two-drug combination, containing at least one new agent, such as vinorelbine, gemcitabine, or the taxanes [8].

Paclitaxel is indicated as a first-line treatment in patients with NSCLC in combination with cisplatin [9]. An important clinical question regarding the taxanes is the issue of the optimal schedule. A preliminary analysis of weekly administration schedules suggest that this approach yields equivalent efficacy results, maintains dose intensity, and is associated with less toxicity [10]. Given these considerations, we decided to start a phase II study of the combination of paclitaxel and cisplatin, giv- en on a weekly basis, in chemo-naïve patients with inoperable or recurrent NSCLC.

\section{Patients and methods}

\section{Eligibility}

Patients were eligible for this study if they had a cytologically or pathologically documented non small-cell lung cancer [11]. Mixed tumours were acceptable if only non-small cell components were identified. A 70 year age limit was established. Patients relapsing after complete tumour resection or patients incompletely resected were also eligible. Patients should have either a measurable or an assessable disease. An Eastern Cooperative Oncology Group (ECOG) performance status [12] of 2 or less was required. Laboratory values at the study entry included leukocyte count higher than $4,000 / \mathrm{mm}^{3}$, platelet count higher than $100,000 / \mathrm{mm}^{3}$, and creatinine and bilirubin blood levels less than 1 and $1 / 2$ times the upper range of normal. The signing of a formal informed consent form, approved by the ALCASE Italia ethical committee, was required.

Patients ineligible were those with a history of second or a third cancer (unless surgically removed and in apparently complete remission). 
Other criteria of ineligibility included mental instability or impairment, pre-existing moderate/severe peripheral neuropathy, previous chemotherapy (including neo-adjuvant or adjuvant chemotherapies).

The study committee for human investigations of the non-profit organisation ALCASE Italia (a unique lung cancer patients' advocacy group in Italy, www.alcase.it) approved the protocol.

\section{Treatment}

Paclitaxel was given weekly at a dose of 80 $\mathrm{mg} / \mathrm{m}^{2}$ for a maximum of 22 weeks of treatment. Paclitaxel was diluted with $100 \mathrm{~mL}$ normal saline and infused intravenously over 60 minutes, followed by $250 \mathrm{~mL}$ normal saline. Cisplatin was administered at a dose of $25 \mathrm{mg} / \mathrm{m}^{2}$, after the paclitaxel infusion, using a standard protocol of premedication and hydration [13]. Premedication consisted of ondansetron 8-16 mg in $100 \mathrm{~mL}$ normal saline, $12 \mathrm{mg}$ dexamethasone, $10 \mathrm{mg}$ clorphenamine, and $50 \mathrm{mg}$ ranitidine given by slow intravenous infusion $30 \mathrm{~min}$ prior to the administration of paclitaxel. Paclitaxel/cisplatin dose adjustments were based on the results of blood counts, hepatic/renal function tests, and the clinical assessment of toxicity, made on the day of treatment. Reductions of $25 \%, 50 \%$ and $75 \%$ of the planned dose were applied for a toxicity grade ranging 0-2 [14]. For higher levels of toxicity, the treatment was withheld and the patient reconsidered 1 -week later.

All patients received full supportive care, including blood product transfusions, haematopoietic growth factors, antibiotics, antiemetics, laxatives, and analgesics as appropriate. Palliative irradiation to painful bone metastases, or brain secondary masses was permitted at any time, and could be concurrent to chemotherapy. Areas treated with radiotherapy were not assessed for tumour response.

Chemotherapy was discontinued on disease progression, patient refusal, or severe toxicity persisting for more than 2 consecutive weeks. Otherwise, it was continued for a maximum of 22 weekly courses.

\section{Staging and Follow-up}

At the study entry, each patient was required to have a baseline clinical work-up, which included medical history, physical examination, blood counts and serum biochemistry, chest x-rays, computed tomography (CT) of the thorax, abdomen and brain, bronchoscopy with cell and tissue biopsies. In addition, all patients were assayed for their plasmatic levels of Carcinoembryonic Antigen (CEA) and Cytokeratin 19 Fragments (Cyfra 21-1) [15]. Additional imaging tests were not mandatory, but requested as clinically indicated. Based on the results of such a re-evaluation, a clinical stage of disease was obtained [16].
During treatment, patients underwent three types of follow-up examinations. The first was a weekly pre-treatment toxicity assessment and consisted of a patient interview - made by the oncology nurse -, haematological counts, and serum biochemistry. Every three weeks, a preliminary reevaluation of the tumour status was made by a physician, on the basis of medical history, physical examination, body weight and ECOG performance status assessment, the standard chest radiogramme and the plasmatic measurement of CEA and Cyfra 21-1. Finally, a complete re-staging evaluation was made at the $12^{\text {th }}$ week of treatment and repeated during the $21^{\text {st }}$ week. Re-staging consisted at least of the same diagnostic procedures used during the baseline pretreatment evaluation except for rebronchoscopy, which was optional.

\section{Toxicity and Response evaluation}

The patients' responses were evaluated by CT scan comparisons and, thus, only at the time of the two protocol-planned restaging evaluations. This choice increased the quality of the objective response assessment, but had the negative effect of reducing the number of observations (to be assessable, patients had to be followed-up until at least the $12^{\text {th }}$ week of treatment).

Toxicity was graded, every week prior to the administration of the cytotoxic drugs, using standard criteria [14]. In addition, we decided to take note of any clinically significant reduction in tumour volume even when it did not fulfill the criteria of partial response. Besides the response categories of complete remission (CR), partial remission (PR), stable disease (SD) and progressive disease (PD) as they are conventionally defined [14], an intermediate category called "Minor Regression" was interposed between PR and SD. Minor regression (MR) was defined as tumour shrinkage comprised between $25 \%$ and $49 \%$ of the pre-treatment size (as measured by the sum of the products of the longest perpendicular diameters of all measurable lesions). In non-measurable assessable lesions, analogous percent changes were used to classify a response as MR. Given our follow-up schedule, tumour responses were considered confirmed by a second evaluation made 3 weeks apart.

\section{Study flow and statistical analysis}

The study was a phase II clinical trial with the following end-points: treatment dose intensity, treatment toxicity, objective response rate, time to treatment failure, and survival. In all, 49 eligible patients were registered on trial, between December 2001 and October 2003. Two patients withdrew their consent before starting the planned treatment, 9 other patients incurred early severe toxicity or had rapid clinical deterioration. Thus, 11 patients were not treated or were inadequately treated having received less than 4 weeks of 
chemotherapy. These eleven patients could not be evaluated for response at the re-staging evaluation time. In addition, another patient of the 49 enrolled was lost to follow-up before their $1^{\text {st }}$ re-staging evaluation. Therefore, we had a total of 47 patients assessable for toxicity, and only 37 for response.

Survival and time to treatment failure were recorded from the day of registration. End-points for survival times were death or the last follow-up contact for patients alive at the closure of the study. Endpoints for treatment failure were the day of the 1 st clinical documentation of PD or the day of the death; for patients alive at the closure of the study and for whom PD was not documented, the end-point for treatment failure was the day of the last follow-up visit.

Kaplan-Meier curves were used to display data [17]. To control for the effect of potential confounders, a multivariate analysis, based on Cox's proportional hazards regression model [18], was performed. For each variable included in the model the proportional hazard assumption was tested graphically.

All statistical comparisons were two-tailed.

\section{Results}

\section{Characteristics of the study cohort}

During the approximate two years of accrual we observed 49 eligible patients, who were registered on study and included in this report.
The clinical characteristics of the 49 patients are depicted in table 1. Characteristics are summarised according to the main end-points of clinical interest (i.e., at study registration and at the closure of the study). Patients were more often males (76\% of the cohort) and in good performance status $(73 \%$ of the cohort had ECOG performance of 0 to 1 ). Tumour markers were only slightly elevated, on average, confirming the overall fairly good prognostic trait of the cohort [19]. Cell types were typically distributed, with a clear prevalence of adenocarcinomas ( $47 \%$ of the whole series). The stage of disease at the study entry was advanced in 13 patients (stage IIIb, 27\%) and very advanced in another 28 subjects (stage IV, 57\%). Two patients entered the study for a recurrent disease after lobectomy or following an intervention of exploratory thoracotomy. Based on the results of the first re-staging evaluation, eleven subjects were considered downstaged to a condition of technical operability, were suspended on chemotherapy for at least 2 weeks and operated upon (23\% of the cohort). Ten other patients were further treated with different regimens of $2^{\text {nd }}$ line chemotherapy, after the $1^{\text {st }}$ line treatment failed (table 1).

\section{Treatment delivery and objective response}

Table 2 summarises the duration and intensity of chemotherapy, and the reasons for stopping it. Thirty-eight patients $(77 \%)$ received more than

Table 1. - Patient demographics and followup information

\begin{tabular}{|c|c|c|c|}
\hline Clinical Characteristics at Registration & median & range & frequency \\
\hline Age (yr) & 63 & $43-70$ & \\
\hline $\operatorname{Sex}(m / f)$ & & & $37 / 12$ \\
\hline ECOG PS $(0 / 1 / 2)$ & & & $5 / 31 / 13$ \\
\hline Weight loss $\left({ }^{\circ}\right)$ & $-6 \%$ & $+6 \% /-17 \%$ & \\
\hline Tumor cell type (S/A/O) & & & $16 / 23 / 10$ \\
\hline \multicolumn{4}{|l|}{ Serum tumor markers: } \\
\hline CEA (ng/ml) & 7 & $1-842$ & \\
\hline Cyfra 21-1 (ng/mL) & 5 & $0-494$ & \\
\hline Stage of disease (IIIa/IIIb/IV) & & & $8 / 13 / 28$ \\
\hline \multicolumn{4}{|l|}{ TNM staging factors: } \\
\hline $\mathrm{T}$ factor $(0 / 1 / 2 / 3 / 4)$ & & & $2 / 4 / 16 / 2 / 25$ \\
\hline $\mathrm{N}$ factor $(0 / 1 / 2 / 3)$ & & & $18 / 1 / 21 / 9$ \\
\hline $\mathrm{M}$ factor $(0 / 1)$ & & & $21 / 28$ \\
\hline Prior surgical treatment (L/ET) & & & $1 / 1$ \\
\hline Followup Information & median & range & frequency \\
\hline \multicolumn{3}{|c|}{ Post-chemotherapy surgical treatment (L/P/AR/ET) } & $7 / 2 / 1 / 1$ \\
\hline \multicolumn{3}{|c|}{ Additional chemotherapy programs at progression $(0 / 1 / 2 / 4)$} & $39 / 9 / 1 / 0$ \\
\hline \multicolumn{3}{|c|}{ Disease status (progressed/not progressed) } & $26 / 23$ \\
\hline \multicolumn{3}{|l|}{ Patient status (dead/alive) } & $23 / 26$ \\
\hline
\end{tabular}

$\left(^{\circ}\right)$ percent body weight loss in 6 months.

Abbreviations:

ECOG PS=Eastern Cooperative Oncology Group performance status; $\mathbf{y r}=$ years; $\mathbf{m}=$ male; $\mathbf{f}=$ female.

Tumor cell type: $\mathrm{S}=$ squamous cell cancer; $\mathrm{A}=$ adenocarcinoma; $\mathrm{O}=$ large cell anaplastic cancer or unclassified non-small cell type. CEA=carcinoembryonic antigen; Cyfra 21-1=cytocheratin 19 fragments.

Surgical treatment: L=lobectomy; $\mathrm{P}=$ pneumonectomy; $\mathrm{AR}=$ atypical resection; $\mathrm{ET}=$ explorative thoracotomy. 
Table 2. - Summary of treatment administration and tumor response

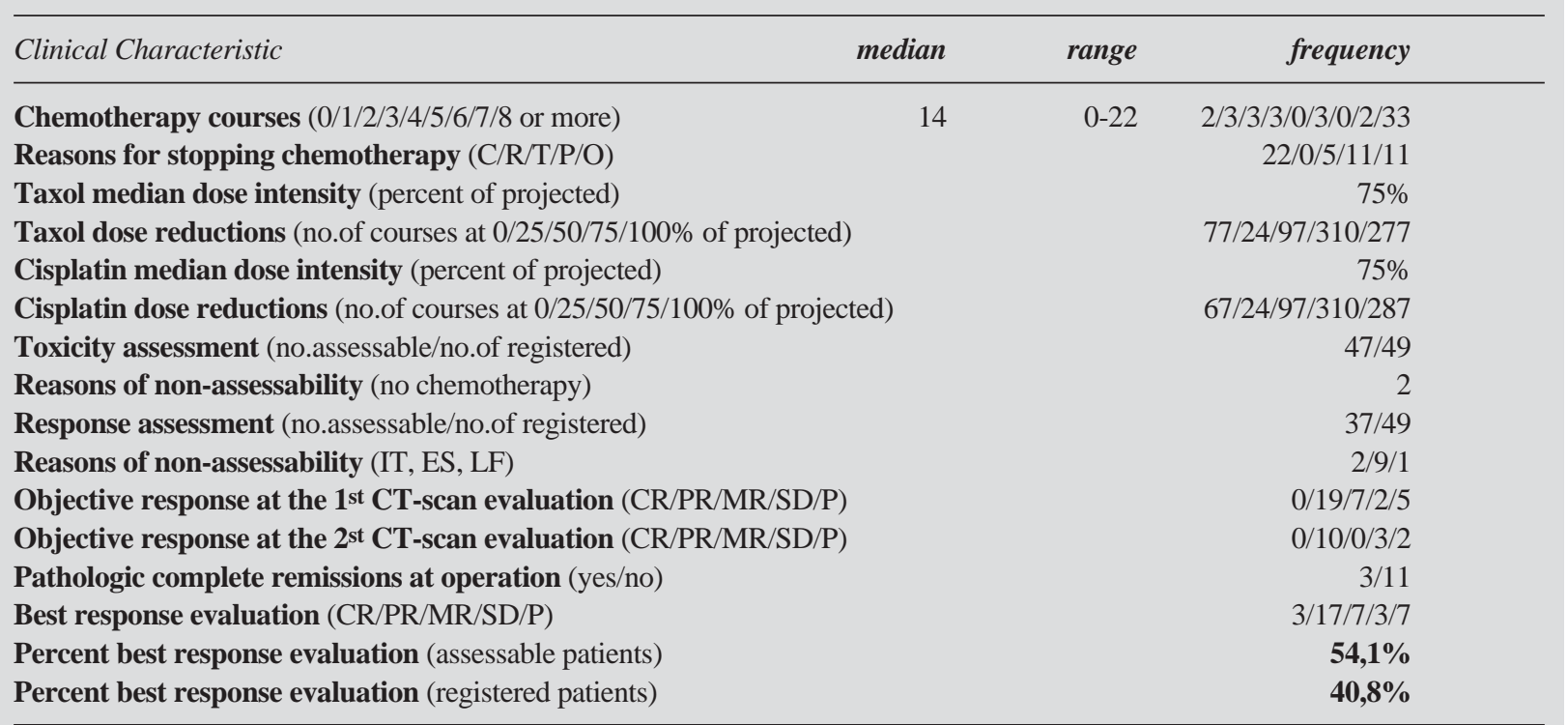

Abbreviations:

Reasons for stopping chemotherapy: $\mathrm{C}=$ completion of the schedule of 22 weeks treatment; $\mathrm{R}=$ patient refusal; $\mathrm{T}=$ unacceptable toxicity; $\mathrm{P}=$ progression; $\mathrm{O}=$ other reasons.

Reasons of non-assessability: IT=no chemotherapy (intent-to-treatment); ES: early chemotherapy suspension (less than 8 cycles) for any cause (except for disease progression); LF, lost in the followup.

CT-scan=computed tomography.

Objective responses: $\mathrm{CR}=$ complete remission, $\mathrm{PR}=$ partial remission, $\mathrm{MR}=$ minor regression, $\mathrm{SD}=$ stable disease, $\mathrm{P}=$ progression.

three chemotherapy courses, which we consider the smallest amount for a valid therapeutic test; the median number of paclitaxel and cisplatin infusions per patient was 14 (range $0-22$ ). The dose intensity was lower than expected $(75 \%)$ for both drugs, with significant dose reductions (table 2). The main reason for stopping treatment was completion of the treatment plan (45\%), followed by progression of disease (22\%).

We observed 3 complete responses (all three pathologically documented after pulmonary resection) and 17 partial responses, for an overall response rate of $54 \%$ (20 patients out of the 37 as- sessable for response) and $41 \%$ (on an intent to treatment basis). Most of the objective responses were already present at the $12^{\text {th }}$ week of treatment $(19 / 20,95 \%)$.

Table 3 provides a summary of the clinical characteristics of the three patients who benefited from a complete, pathologically documented, response.

\section{Toxicity}

Toxicity was measured at each week, during treatment, for a total of 785 observations (table 4).

Table 3. - Clinical characteristic of complete responding patients

\begin{tabular}{|c|c|c|c|c|c|c|c|c|c|c|c|c|c|c|}
\hline \multicolumn{8}{|c|}{ Pre-Treatment Data } & \multicolumn{5}{|c|}{ Treatment and Post-Treatment Data } & \multicolumn{2}{|c|}{ Follow-up data } \\
\hline $\begin{array}{l}\text { Patient } \\
\text { Initials }\end{array}$ & $\begin{array}{r}\text { Sex } \\
(M / F)\end{array}$ & $\begin{array}{c}\text { Age } \\
\text { (years) }\end{array}$ & ECOG PS & $\begin{array}{c}\text { CEA } \\
(\mathrm{ng} / \mathrm{ml})\end{array}$ & $\begin{array}{c}\text { Cyfra 21-1 } \\
\text { (ng/mL) }\end{array}$ & $\begin{array}{l}\text { Tumor } \\
\text { cell type }\end{array}$ & $\begin{array}{c}\text { Stage } \\
\text { of Disease }\end{array}$ & $\begin{array}{c}\text { Type } \\
\text { of Surgery }\end{array}$ & $\begin{array}{l}\text { Pathologic } \\
\text { Stage }\end{array}$ & $\begin{array}{c}\mathrm{OR} \\
\left(1^{\text {st }} \text { restaging }\right)\end{array}$ & 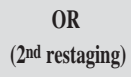 & $\begin{array}{c}\text { Duration of } \\
\text { Response (wks) }\end{array}$ & $\begin{array}{l}\text { Additional } \\
\text { Treatments }\end{array}$ & $\begin{array}{c}\text { Overall } \\
\text { survival (wks) }\end{array}$ \\
\hline G.C. & M & 64 & 1 & 3 & 4,7 & $\mathrm{E}$ & IIIA & Lingulectomy & TONO & PR & PR & 85 & $2^{\text {nd }}$ line $\mathrm{CT}$ & $93+$ \\
\hline B.B. & M & 65 & 2 & 12 & 13,8 & $\mathrm{E}$ & IIIA & Lobectomy & TONO & PR & NA & $64+$ & I & $64+$ \\
\hline P.M. & $\mathrm{F}$ & 57 & 1 & 1 & 1,7 & $\mathrm{E}$ & IIIB & Lobectomy & TONO & PR & NA & $58+$ & / & $58+$ \\
\hline Median & / & 64 & 1 & 3 & 5 & / & / & I & I & l & / & $58+$ & I & $64+$ \\
\hline
\end{tabular}

Abbreviations:

$\mathbf{M}=$ male, $\mathbf{F}=$ female; ECOG PS=Eastern Cooperative Oncology Group performance status; wks=weeks; $\mathbf{R T}=$ radiotherapy; $\mathbf{O R}=$ objective response.

CEA=carcinoembryonic antigen; Cyfra 21-1=cytocheratin 19 fragments; CT=chemotherapy.

Tumor cell type: E=epidermoid-squamous cell cancer.

Objective responses: $\mathrm{PR}=$ partial remission; $\mathrm{NA}=$ not available. 
Table 4. - Toxic events (785 pre-infusion assessments)

\begin{tabular}{|c|c|c|c|c|c|c|c|c|c|c|c|}
\hline \multirow{2}{*}{ Toxicity grade (ECOG scale) } & \multicolumn{2}{|c|}{0} & \multicolumn{2}{|c|}{1} & \multicolumn{2}{|c|}{2} & \multicolumn{2}{|c|}{3} & \multicolumn{2}{|c|}{4} & \multirow{2}{*}{ TOTAL } \\
\hline & no. & $\%$ & no. & $\%$ & no. & $\%$ & no. & $\%$ & no. & $\%$ & \\
\hline Haemoglobin & 643 & $83,2 \%$ & 91 & $11,8 \%$ & 27 & $3,5 \%$ & 10 & $1,3 \%$ & 2 & $0,3 \%$ & 773 \\
\hline Leukocytes & 646 & $84,0 \%$ & 55 & $7,2 \%$ & 45 & $5,9 \%$ & 12 & $1,6 \%$ & 11 & $1,4 \%$ & 769 \\
\hline Platelets & 761 & $98,4 \%$ & 6 & $0,8 \%$ & 3 & $0,4 \%$ & 0 & $0,0 \%$ & 3 & $0,4 \%$ & 773 \\
\hline Renal (creatinine) & 767 & $99,4 \%$ & 4 & $0,5 \%$ & 1 & $0,1 \%$ & 0 & $0,0 \%$ & 0 & $0,0 \%$ & 772 \\
\hline Nausea-vomiting & 670 & $85,4 \%$ & 99 & $12,6 \%$ & 16 & $2,0 \%$ & 0 & $0,0 \%$ & 0 & $0,0 \%$ & 785 \\
\hline Diarrhoea & 743 & $94,6 \%$ & 31 & $3,9 \%$ & 9 & $1,1 \%$ & 2 & $0,3 \%$ & 0 & $0,0 \%$ & 785 \\
\hline Stomatitis & 709 & $90,3 \%$ & 75 & $9,6 \%$ & 1 & $0,1 \%$ & 0 & $0,0 \%$ & 0 & $0,0 \%$ & 785 \\
\hline $\begin{array}{l}\text { Hypersensitivity } \\
\text { reactions }\end{array}$ & 728 & $92,7 \%$ & 48 & $6,1 \%$ & 6 & $0,8 \%$ & 3 & $0,4 \%$ & 0 & $0,0 \%$ & 785 \\
\hline Hydric retention & 730 & $93,0 \%$ & 46 & $5,9 \%$ & 9 & $1,1 \%$ & 0 & $0,0 \%$ & 0 & $0,0 \%$ & 785 \\
\hline Alopecia ${ }^{\circ}$ & 384 & $48,9 \%$ & 87 & $11,1 \%$ & 162 & $20,6 \%$ & 152 & $19,4 \%$ & 0 & $0,0 \%$ & 785 \\
\hline $\begin{array}{l}\text { Local reaction } \\
\text { at the site of } \\
\text { intravenous injection }\end{array}$ & 785 & $100,0 \%$ & 0 & $0,0 \%$ & 0 & $0,0 \%$ & 0 & $0,0 \%$ & 0 & $0,0 \%$ & 785 \\
\hline Neuropathy & 701 & $89,3 \%$ & 80 & $10,2 \%$ & 4 & $0,5 \%$ & 0 & $0,0 \%$ & 0 & $0,0 \%$ & 785 \\
\hline $\begin{array}{l}\text { Respiratory infections } \\
\text { with leukopenia }\end{array}$ & 753 & $95,9 \%$ & 32 & $4,1 \%$ & 0 & $0,0 \%$ & 0 & $0,0 \%$ & 0 & $0,0 \%$ & 785 \\
\hline Bronchodynamic toxicity & 746 & $95,0 \%$ & 24 & $3,1 \%$ & 13 & $1,7 \%$ & 2 & $0,3 \%$ & 0 & $0,0 \%$ & 785 \\
\hline
\end{tabular}

$\left({ }^{\circ}\right)$ partially due to the concurrent brain irradiation given to 3 patients.

Abbreviations:

ECOG=Eastern Cooperative Oncology Group.

The most common toxicity was alopecia $(51 \%$ in all), neuropathy (never severe), anemia, and leukopenia (never associated with life-threatening infections). In total, a grade 3 or 4 toxicity (except alopecia) was found in only 45 of the 785 observations $(6 \%)$. There were no documented toxic deaths. Anemia was in general mild and notnecessarily treatment-related (table 4). Other common, non-alarming toxicities were nausea/vomiting, diarrhea, stomatitis and hypersensitivity reactions, including dermatitis and flu-like symptoms.

\section{Time to treatment failure and survival}

As at December 2003, 23 patients have died. The median follow-up time was 32 weeks (range 6-108). Overall, the estimated median survival was 56 weeks (table 5). The estimated median time to progression was 35 weeks (quartile range: 29-41) (table 5). Figures 1 and 2 outline the Kaplan-Meier estimates for time to progression and overall survival.

\section{Discussion}

The goal of this phase II study was to make a comprehensive evaluation of the activity and toxicity of a new weekly schedule of the cisplatin/paclitaxel combination for the front-line treatment of advanced NSCLC.

Platinum-based chemotherapy is the standard for the treatment of young, well-performing patients with metastatic NSCLC $[6 ; 20]$ and most authors regard the doublet cisplatin (or carboplatin)/paclitaxel as a standard chemotherapy regimen [21-24]. In chemo-naïve patients, singleagent-paclitaxel has been studied on different

Table 5. - Time to Progression and Survival

\begin{tabular}{lccccccc}
\hline UNIVARIATE ANALYSES & no. & at risk & median $^{\circ}$ & $\mathbf{9 5 \%}$ CI & IQ range & 1-yr \% $^{\circ}$ & $\mathbf{2 - y r}^{\circ}$ \\
\hline Time to progression analysis (fig. 1) & 49 & 23 & 34,9 & $29.0-40.7$ & $22.9-64.4$ & $36,9 \%$ & $0,0 \%$ \\
Survival analysis (fig. 2) & 49 & 26 & 55,9 & NC & NC & $50.7 \%$ & $46,1 \%$ \\
\hline
\end{tabular}

$\left(^{\circ}\right)$ time is expressed in weeks.

Abbreviations:

no.=number of patients availble for analysis; $\mathbf{C I}=$ confidence interval; $\mathbf{I Q = i n t e r q u a r t i l e ~ r a n g e ; ~} \mathbf{y r}=y e a r ; \mathbf{N C}=$ not calculable . 


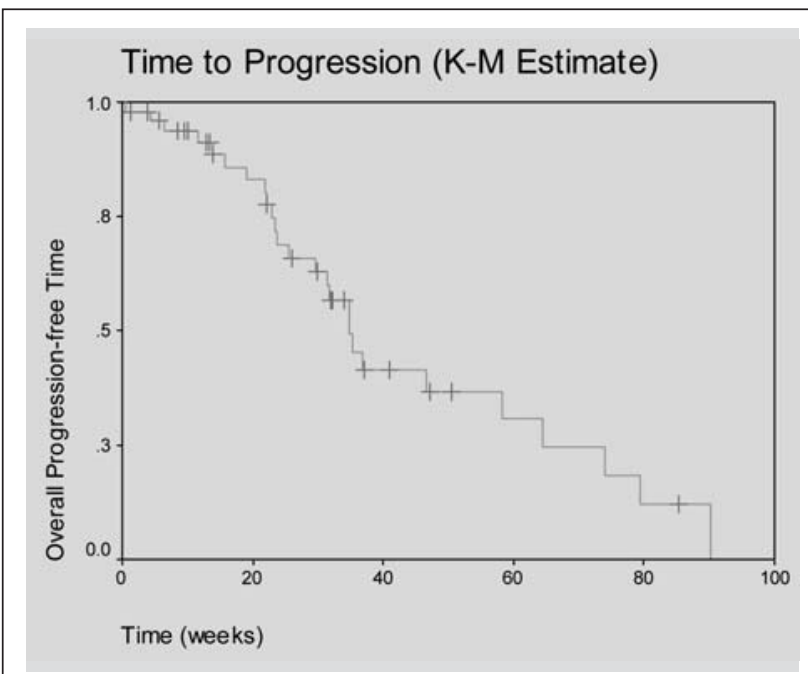

Fig. 1. - Kaplan and Meier estimate of treatment failure for the whole group of patients.

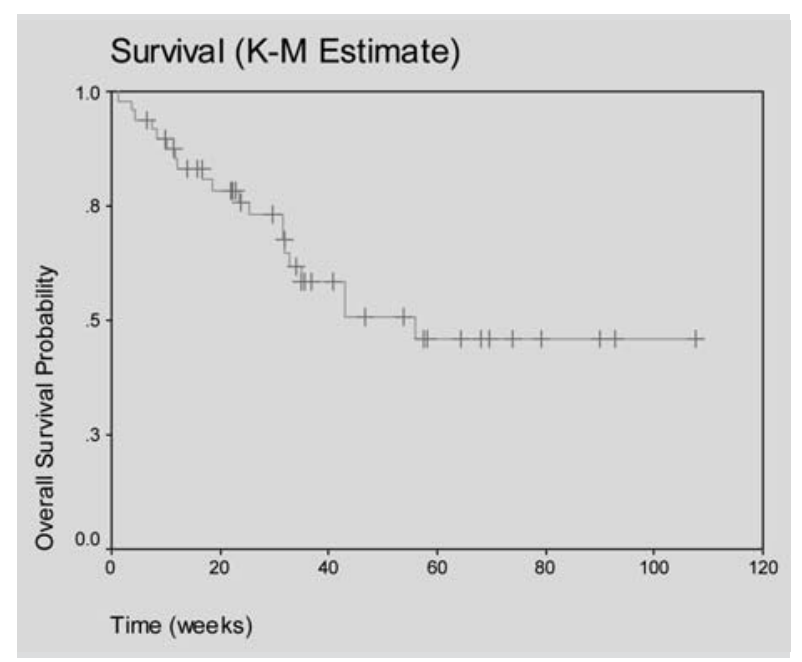

Fig. 2. - Kaplan and Meier estimate of survival for the whole group of patients.

schedules and doses, with response rates ranging 21-24\% and median survivals ranging from 6 to 9 months [25]. Single-agent weekly paclitaxel, at doses ranging from 50 to $200 \mathrm{mg} / \mathrm{m}^{2} /$ week, has been associated with response rates of $23-56 \%$ and acceptable toxicity [26].

Weekly paclitaxel has been combined with carboplatin and vinorelbine in two-drug combinations and with cisplatin plus gemcitabine and cisplatin plus vinorelbine in three-drug regimens [26]. Between 2003 and 2004, the activity/toxicity of weekly paclitaxel combined with cisplatin has been reported in three consecutive studies [27-29].

A regime of weekly low-dose paclitaxel/cisplatin was reported by Kim et al. [27] Paclitaxel $\left(40 \mathrm{mg} / \mathrm{m}^{2}\right)$ and cisplatin $\left(20 \mathrm{mg} / \mathrm{m}^{2}\right)$ were administered weekly, without interruption, in 22 chemonaïve patients with NSCLC. With a median of 16 weekly cycles of chemotherapy, the objective response rate was $40.9 \%$ (95\% CI, 18.6-63.2\%). Stable diseases and progressive diseases accounted for 40.9 and $18.2 \%$, respectively. The median duration of response was 3 months (1-12 months). Myelosuppression was not noted and non-haema- tologic toxicities were mild. The authors concluded that weekly low dose chemotherapy with paclitaxel and cisplatin could be given safely to the patients with NSCLC [27]. This study had a treatment schedule identical to the our schedule, but the dose of paclitaxel was half of ours.

More recently, Yoshimura and co-workers conducted a phase I/II trial to determine the maximum-tolerated dose (MTD) and the recommended dose (RD) of paclitaxel administered weekly with a fixed dose of cisplatin, and to assess the toxicity and activity of this combination [29]. In this study, patients with stage IIIB/IV NSCLC were eligible. Paclitaxel, at a starting dose of $40 \mathrm{mg} / \mathrm{m}^{2} /$ week on days 1,8 , and 15 , was combined with a fixed dose of cisplatin $80 \mathrm{mg} \mathrm{m}^{2}$ on day 1 . Chemotherapy was given in a 4-week cycle. Thirty-eight patients were enrolled. Dose-limiting toxicities (DLT) were neutropenia, fatigue, and omission of treatment due to leucopenia, thrombocytopenia, or febrile neutropenia. The MTD and RD for paclitaxel were estimated to be $70 \mathrm{mg} / \mathrm{m}^{2}$. Of the 37 assessable patients, 23 had a partial response and one had a complete response. Overall response rate was $62.1 \%$ (95\% CI: 46.5-77.7\%). The progressionfree survival, the median survival time, and the 1year survival rate were 5.5 months, 13.7 months, and $56.9 \%$, respectively. This regimen was less comparable with our regimen, especially because of the timing and fractionation of cisplatin. However, it was similarly tolerable and even more active. The authors suggested that its efficacy should be confirmed in a phase III study [29].

A few weeks later, a phase III study comparing weekly paclitaxel plus cisplatin vs. vinorelbine plus cisplatin in 140 chemo-naïve NSCLC patients was reported [28]. The treatment dose [28] was paclitaxel $66 \mathrm{mg} / \mathrm{m}^{2}$ on days 1,8 , and 15 , and cisplatin $60 \mathrm{mg} / \mathrm{m}^{2}$ on day 15 , or vinorelbine $23 \mathrm{mg} /$ $\mathrm{m}^{2}$ on days 1,8 , and 15 , and cisplatin $60 \mathrm{mg} / \mathrm{m}^{2}$ on day 15 , every 4 weeks. There were 26 partial responses and one complete response (overall $38.6 \%$ ) in the paclitaxel arm, and 27 partial responses (overall $38.6 \%$ ) in the vinorelbine arm. Myelosuppression was more common in the vinorelbine arm $(\mathrm{p}<0.001)$. Peripheral neuropathy and myalgia were more common in the paclitaxel arm $(p<0.001)$. The median time to disease progression was 6 months in the paclitaxel arm and 8.4 months in the VC arm $(p<0.05)$. The median survival time was 11.7 months in the paclitaxel arm and 15.4 months in the vinorelbine arm $(\mathrm{p}=\mathrm{NS})$. Also in this trial the cumulative doses of paclitaxel and cisplatin were significantly less than ours and the weekly scheduling of the combination was partial.

The current study used a complete weekly fractionation of the total amount of paclitaxel/cisplatin delivered, which, on average, was the highest so far. With this schedule, we have shown that the combination of cisplatin/paclitaxel is a highly effective therapeutic option, and is associated with low toxicity. Remarkably, it seems to increase long-term survival (46\% alive at 2-years). Thirtyeight patients $(78 \%$ of the study cohort) were able 
(and willing) to continue the assigned treatment for a duration of treatment that can be considered sufficiently long (4 weeks or more). 37 of the 49 registered patients could be reassessed at the first planned restaging time and were assessable for response. In this group, the weekly regimen was highly effective (54\% of responses), even when compared to the best results reported so far $(62 \%)$ [29]. As in any of the previous reports, toxicity was mild and manageable, with no major toxicity event. Importantly, the survival duration of the whole group of 49 patients was the most favorable reported so far.

In conclusion, we have shown that the weekly administration of paclitaxel and cisplatin is a valid therapeutic option for front-line treatment of inoperable NSCLC. It may be used in young, good performance status patients who have no significant co-morbidity, but the low toxicity profile suggests that it may represent a sufficiently safe therapeutic option also in unfit and/or elderly patients.

Acknowledgments: The authors wish to thank Mrs. Anna Merlo and Mrs. Barbara Barison, nurses of their outpatient unit, for the invaluable help and support.

\section{References}

1. Greenlee RT, Hill-Harmon MB, Murray T, et al. Cancer statistics, 2001. CA Cancer J Clin 2001; 51: 15-37.

2. American Thoracic Society, European Respiratory Society. Pretreatment Evaluation of Non-Small-cell Lung Cancer. Am J Respir Crit Care Med 1998; 156: 320-32.

3. Buccheri G. Chemotherapy and survival in non-small cell lung cancer. The old 'vexata questio'. Chest 1991; 99: 1328-9.

4. Buccheri G. Chemotherapy and survival in non-small cell lung cancer: Three years later. Chest 1994; 106: 990-2.

5. Alberti W, Anderson G, Bartolucci A, et al. Chemotherapy in non-small cell lung cancer: A meta-analysis using updated data on individual patients from 52 randomised clinical trials. British Medical Journal 1995; 311: 899909.

6. American Society of Clinical Oncology. Clinical Practice Guidelines for Treatment of Unresectable NonSmall-Cell Lung Cancer. J Clin Oncol 1998; 15: 29963018.

7. Gatzemeier U. Indications for chemotherapy in stage IV non-small cell lung cancer. Lung Cancer 2001; 33 Suppl 1: S109-S113.

8. Bunn PA, Jr. Chemotherapy for advanced non-smallcell lung cancer: who, what, when, why? J Clin Oncol 2002; 20 Suppl 1: 23S-33S.

9. Schiller JH, Harrington D, Belani CP, et al. Comparison of four chemotherapy regimens for advanced nonsmall-cell lung cancer. $N$ Engl J Med 2002; 346: 92-8.

10. Koumakis G, Demiri M, Barbounis V, et al. Is weekly paclitaxel superior to paclitaxel given every 3 weeks? Results of a phase II trial. Lung Cancer 2002; 35: 315-7.

11. World Health Organization. International histological classification of tumours. Berlin: Springer-Verlag, 1991.
12. Zubrod CG, Scheiderman MA, Frei E, et al. Appraisal of methods for the study of chemotherapy in man: comparative therapeutic trial of nitrogen mustard and triethylene thiophosphoramide. J Chron Dis 1960; 11: 7-33.

13. Buccheri G, Ferrigno D. Efficacy of platinum-based regimes in non-small cell lung cancer. A negative report from the Cuneo Lung Cancer Study Group. Lung Cancer 1997; 18: 57-70.

14. Miller AB, Hoogstraten B, Staquet M, Winkler A. Reporting results of cancer treatment. Cancer 1981; 47: 207-14.

15. Buccheri G, Ferrigno D. Cytokeratin-derived markers of lung cancer. Expert Rev Mol Diagn 2001; 1: 315-22.

16. Mountain CF. Revisions in the International System for Staging Lung Cancer [see comments]. Chest 1997; 111: 1710-7.

17. Kaplan EL, Meier F. Non-parametric estimation from incomplete observations. J Am Stat Assoc 1958; 58: 457-81.

18. Cox DR. Regression models and life tables. J R Stat Soc 1972; 34: 187-220.

19. Buccheri G. Tumor Markers: Clinical Meaning and Use. In: Brambilla C, Brambilla E. Lung Tumors, vol. 124, 1 ed. New York: Marcel Dekker, Inc., 1999: 435-52.

20. National Cancer Institute. PDQ. Treatment.Health Professionals. Non-small cell lung cancer. 2002. http: //cancernet.nci.nih.gov/clinpdq/soa/Non-small_cell_ lung_cancer_Phisician.htlm.

21. Bonomi P. Review of paclitaxel/carboplatin in advanced non-small cell lung cancer. Seminars in Oncology 1999; 26: 55-9.

22. Scagliotti GV, De Marinis F, Rinaldi M, et al. Phase III randomized trial comparing three platinum-based doublets in advanced non-small-cell lung cancer. $J$ Clin Oncol 2002; 20: 4285-91.

23. Vokes EE, Herndon JE, Crawford J, et al. Randomized phase II study of cisplatin with gemcitabine or paclitaxel or vinorelbine as induction chemotherapy followed by concomitant chemoradiotherapy for stage IIIB nonsmall-cell lung cancer: cancer and leukemia group B study 9431. J Clin Oncol 2002; 20: 4191-8.

24. Kelly K, Crowley J, Bunn PA, Jr, et al. Randomized phase III trial of paclitaxel plus carboplatin versus vinorelbine plus cisplatin in the treatment of patients with advanced non-small-cell lung cancer: a Southwest Oncology Group trial. J Clin Oncol 2001; 3210-8.

25. Socinski MA. Single-agent paclitaxel in the treatment of advanced non-small cell lung cancer. The Oncologist 1999; 408-16.

26. Alberola V, Cortesi E, Juan O. Weekly paclitaxel in the treatment of metastatic and/or recurrent non-small cell lung cancer. Crit Rev Oncol Hematol 2002; 44 Suppl: 31-41.

27. Kim SW, Suh C, Lee SD, et al. Weekly low dose paclitaxel and cisplatin as first-line chemotherapy for advanced non-small cell lung cancer. Lung Cancer 2003; 41: 221-6.

28. Chen YM, Perng RP, Shih JF, et al. A randomised phase II study of weekly paclitaxel or vinorelbine in combination with cisplatin against inoperable nonsmall-cell lung cancer previously untreated. Br J Cancer 2004; 90: 359-65.

29. Yoshimura N, Kudoh S, Mukohara T, et al. Phase I/II study of cisplatin combined with weekly paclitaxel in patients with advanced non-small-cell lung cancer. Brit J Cancer 2004; 90: 1184-9. 